\title{
Some Unrecorded Genera and Species in Korean Agaricales (II)
}

\author{
Soon Ja Seok ${ }^{1 *}$, Yun A Jung ${ }^{1}$, Yong Ju Jin ${ }^{1}$, In Cheol Park ${ }^{1}$, Soon Woo Kwon ${ }^{1}$, Yang Sup Kim ${ }^{1}$ \\ and Kwan Hee Yoo ${ }^{2}$ \\ ${ }^{1}$ Agricultural Microbiology Team, National Academy of Agricultural Science, Rural Development Administration, Suwon 441-707, Korea \\ ${ }^{2}$ Dept. Biology, Sang-ji University, Wonju, 220-702, Korea
}

(Received 14, November 2011., 1st Revised 17, November 2011., Accepted 23, November 2011)

\begin{abstract}
The investigation on the species diversity for the Korean fungal flora was carried out by authors. Five species of the Agaricales recorded in the present paper are distributed Hygrocybe laeta (Pers.)P. Kummer var. laeta, Lyophyllum tylicolor (Fr.) M. Lange \& Sivertsen, Clitopilus scyphoides (Fr.) Singer, var. scyphoides, Entoloma rusticoides (Gillet) Noordel. and Lactarius uyedae Singer were recorded for the first time and are described and illustrated in detail. Specimens cited here are deposited in the Herbarium Conservation Center of National Academy of Agricultural Sciences.
\end{abstract}

KEYWORDS : Clitopilus scyphoides var. scyphoides, Entoloma rusticoides, Hygrocybe laeta var. laeta, Lactarius uyedae, Lyophyllum tylicolor, Fungal flora, Unrecorded species

\section{서 론}

국내에 자생하는 주름버섯목의 종다양성 조사와 분포상 조사를 위하여 1993-1999년까지 제주도 서귀포시 등 3곳 에서 수집하여 농촌진흥청 국립농업과학원 식물균류표본 보존실 $(\mathrm{HCCN})$ 에 보존하고 있는 표본에 대해 미세구조 등을 관찰한 결과, 그 중에서 국내 균류 종다양성 목록에 없는 미기록 5종 (장미무명버섯 Hygrocybe laeta var. laeta, 애 만가닥버섯 Lyophyllum tylicolor, 흰그늘버섯 꼬마외대버섯 Clitopilus scyphoides f. omphaliformis, Entoloma rusticoides, 치마젓버섯 Lactarius uyedae)이 확인되어 미세구조를 관 찰하고 특징을 기술하여 보고하고자 한다.

\section{재료 및 방법}

버섯류의 조사관찰을 위하여 국립농업과학원 식물균류 표본실에 보관 중인 Hygrocybe sp. 등 5표본을 활용하였다. 조사대상 버섯의 발생환경 및 자실체의 육안적 특징은 현장 에서 기록한 조사야장과 자실체 사진을 참조하였다. 자실체의 미세구조(포자, 담자기, 날시스티디아, 측시스티디아, 갓시스 티디아, 대시스티디아 자실층 조직 및 균사의 협구 유무 등)관

\footnotetext{
$\overline{\text { *Corresponding }}$ author <E-mail : mycena@korea.kr>
}

찰은 자실체(자실층 포함)를 잘라 2-3 mm의 절편을 만든 다 음 그 절편을 물 $\left(\mathrm{H}_{2} \mathrm{O}\right)$ 과 $70 \%$ 알코올에 각각 침지시켜 조직이 원상태로 부풀 때까지 반복한다. 조직의 절편을 수수깡에 넣 고 양면 면도날로 박편을 만들어 슬라이드 글라스 위에 놓은 다음 커버글라스를 덮는다. 조직의 화학반응을 확인하기 위해 Melzer's 용액, $1 \%$ phloxine용액 또는 congo red 등으로 염색을 하여 현미경하에서 400 배 또는 1000 배로 확대하 여 미세구조를 관찰하였다. 버섯의 분류체계는 Singer(1986) 의 분류체계를 기본으로 하였으며, 일부분은 Imazeki와 Hongo(1987)의 제안을 참조하였다. 종 동정은 각 과(families) 또는 속(genus)의 전문가의 특징기술을 참조하였다. 색명 및 괄호 안의 색 기호는 Kornerupt과 Wanscher(1978)의 Methuen Hand book of Color을 참조하여 기술하였다.

\section{결과 및 고찰}

장미무명버섯(신칭) Hygrocybe laeta (Pers.)P. Kummer Führ. Pilzk. (Zwickau): 112 (1871) var. laeta

Synonymy. Agaricus laetus Pers., Observ. mycol. (Lipsiae) 2: 48 (1800) [1799]

Gliophorus laetus (Pers.) Herink, Sb. severoèeského Musea, Historia Naturalis 1: 84 (1958) 
Hygrocybe laeta (Pers.) P. Kumm., Führ. Pilzk. (Zwickau): 112 (1871)

Hygrophorus houghtonii Berk. \& Broome [as 'houghtoni'], Ann. Mag. nat. Hist., Ser. 4 11: 342 (1873)

Hygrophorus laetus (Pers.) Fr., Epicr. syst. mycol. (Upsaliae): 329 (1838) [1836-1838]

\section{Macroscopic features (Fig. 1A, 2A, 3A).}

Pileus. $8-23 \mathrm{~mm}$ wide, when young convex, then plano-convex to plane, sometimes usually with depressed at center, margin somewhat crenulate. surface smooth, pale red to pinkish white(7-8A2-3) or orange white to pale orange (5-6A2-3), glutinous viscid, translucent striate almost to the center when wet. context thin, fragile, odor indistinct, taste mild.

Lamellae. arched-decurrent, $\operatorname{distant}(\mathrm{L}=13-16)$, whitish, edge smooth. lamellulae usually 2-tiers, but rarely 3-tiers.

Stipe. 45-104 × 1.5-3 mm, cylindric, equal, tapering upwards, often slightly curved, surface smooth, concolorous with pileus, but paler downwards, orange white to pale orange(5A2-3)
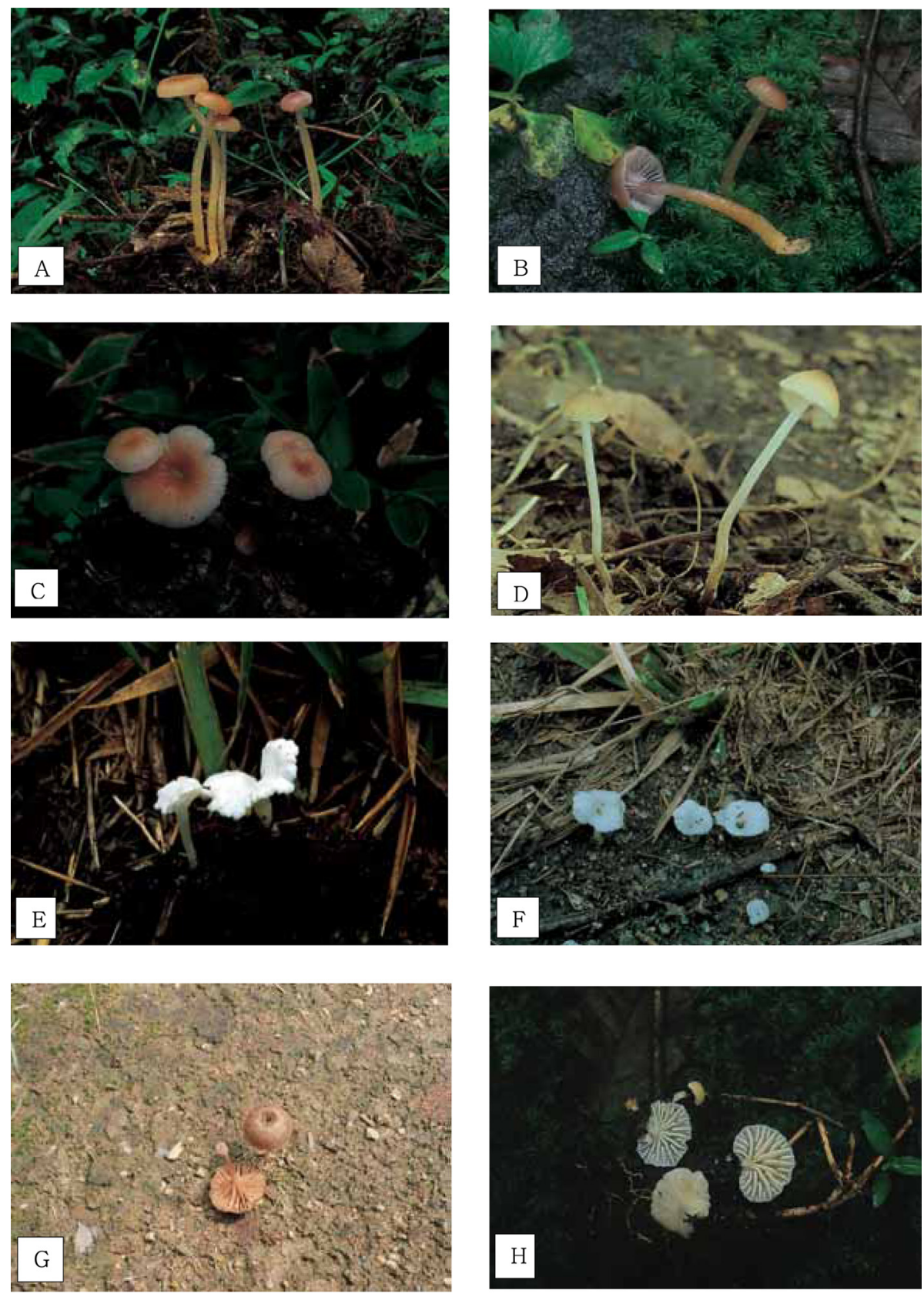

Fig. 1. Carphophores of Hygrocybe laeta var. laeta. A, B, C; Lyophyllum tylicolor D; Clitopilus scyphoides var. scyphoide. E, F; Entoloma rusticoides. G; Lactarius uyedae. $\mathrm{H}$. 
at the base, with translucent cross band, strongly glutinous (ca.1 mm thick). hollow.

\section{Microscopic features (Fig. 2).}

Spores 5.5-7.3 $\times$ 4.6-5.5 $\mu \mathrm{m}$, broadly elliptic, smooth, thin-walled, hyaline, inamyloid, with a droplet. Basidia 28.2-41.5 × 5-6.4 $\mu \mathrm{m}$, usually 4-spored, rarely 2-spored, sterigmata very long $6.4-18.2 \mu \mathrm{m}$ long, with a basal clamp, some of which are medallion clamps. Cheilocystidia and Pleurocystidia not seen. Hymenophoral trama subparallel. Pileipellis an ixotrichoderm of erect hyphae 0.5-1.2 $\mu \mathrm{m}$ across, embedded in a gelatinous substance, septa without clamp connections. Stipitipellis composed of parallel 1.1-6 $\mu \mathrm{m}$ across, cylindric, hyaline, tnin-walled.

Habit \& Habitat. Later summer to Fall, gregarious or grouped among mosses in forests, very rare.

Specimens examined. Jungmoon, Seoguipo-si, Jeju-do,
September 6. 1999 (HCCN:7866A), Collected by S. J. Seok

Remarks. This taxa belongs to the Section Subglutinous, Subsection Subglutinosae in having the glutinous or simy pileus and stipe. Hygrocybe psittacinea is closely related with this taxa. H. psittacinea is characterized by the fruit bodies with green tones.

갓 크기는 8-23 mm로 성장초기에는 반반구형이나 성장하 편평상반반구형-편평 하게 펴지며, 종종 중앙부위가 약간 움푹하게 되고, 갓 끝은 종종 규칙적으로 조 개형의 굴곡이 있다. 표면은 평활하고, 옅은적색-분홍백색 또는 등황백색옅은등 황색을 때며, 젤라틴질이고, 습할 때 반투명선이 거의 중앙부위까지 있다. 조직은 얇고, 잘 부서지며, 냄새는 불 분명하고, 맛은 부드럽다.

주름살은 아취상 내린주름살이고, 성글며(긴주름살 1316 개), 백색이고, 주름살 날은 평활하며, 짧은 주름살은 대 부분 2가지형이나 드물게는 3가지형도 있다.

대는 크기가 45-104 × 1.5-3 mm로 원통형이고, 상하굵

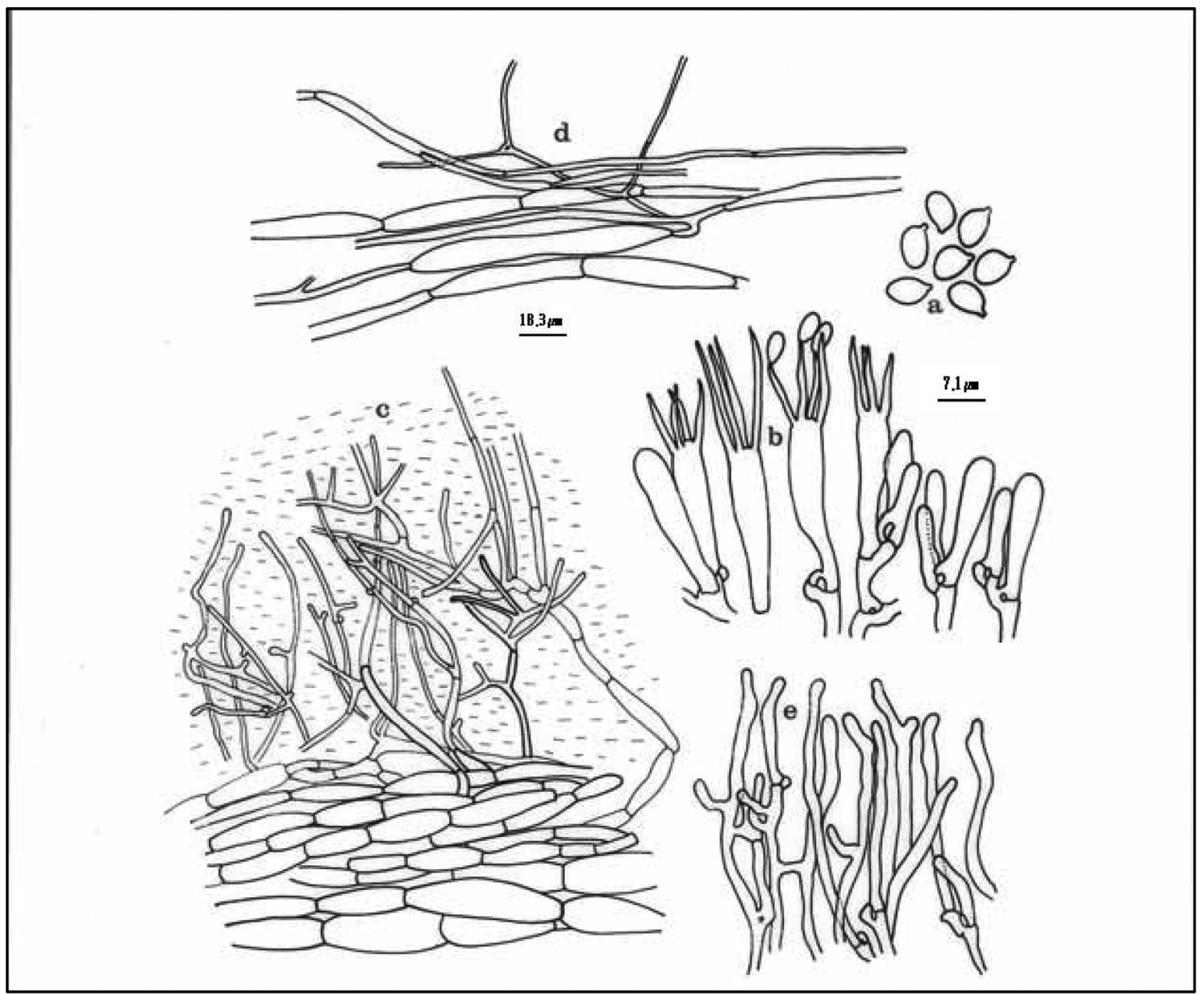

Fig. 2. Microscopic structures of Hygrocybe laeta var. laeta. A. spores $(\times 1,000)$, B. basidia $(\times 1,000)$, C. pileipellis $(\times 400)$, D. stipitipellis $(\times 400)$. E.termial cell of pileipellis $(\times 400)$. 
기가 비슷하거나 상부 쪽이 다소 가늘며, 종종 굽어있다. 표면은 평활하고, 갓과 같은 색이나 기부 쪽으로 옅은 색을 띠며, 기부는 등황백색-옅은등황색을 띠고, 반투명한 띠가 나타나며, 습할 때 현저한 젤라틴질이 덮혀 있다. 대 속은 비어 있다.

포자문은 백색이며, 포자는 크기가 5.5-7.3 × 4.6-5.5 $\mu \mathrm{m}$ 로 넓은 타원형이고 평활하며, 포자벽은 얇고, 무색이며, 비아밀로이드이고, 커다란 기포가 있다. 담자기는 크기가 28.2-41.5 $\times$ 5-6.4 $\mu \mathrm{m}$,로 대부분 4포자형이나 드물게는 2 포자 형 도 있으며, 담자뿔이 현저하게 길고(6.4-18.2 $\mu \mathrm{m}$ 길이), 기부에 협구가 있으며, 드물게는 반지협구(medallion clamps) 가 있다. 날시스티디아와 측시스 티디아는 없다. 자실층조 직은 유평행형이며, 갓표피상층은 굵기가 0.5-1.2 $\mu \mathrm{m}$ 인 직립균사가 젤라틴질속에 있다. 균사에 협구는 보이지 않 는다. 대표피상층은 폭이 1.1-6 $\mu \mathrm{m}$ 인 평행균사로 구성되어 있으며, 무색이고, 세포벽은 앏다.

발생시기 및 장소 : 늦은 여름-가을에 혼합림내 주로 이 끼가 많은 토양 또는 부후목 주위에 소수군생-무리져 발 생한다. 매우 희귀종이다.

시험재료 : 제주도 서귀포시 중문, 1999. 9. 6. (HCCN: 7866A), 채집자: 석순자.

관찰 : 본 종은 갓과 대에 젤라틴질이 있다는 점에서 Section Su glutinous, Subsection Subglutinosae에 속한다. 유 사종으로서 Hygrocybe psittacinea가 있다. H. psittacinea 갓과 대에 녹색을 떤다는 점이 다르다.

애만가닥버섯(신칭) Lyophyllum tylicolor (Fr.) M. Lange \& Sivertsen, Bot. Tidsskr. 62 : 205 (1966)
Synonymy. Tephrocybe tylicolor (Fr.) M.M. Moser, in Gams 1978

\section{Macroscopic features (Fig. 1D)}

Pileus. 4-15 mm broad, conico-campannulate to hemispheric when young, later convex, finally plane, always with a umbo. surface dry, smooth to more or less pruinose when young, later slightly fibrilose, orange white to pale orange white(5A2) towards margin, dark blond(5D4), red-haired to sahara(6C4-5) or camel to sunburn(6D4-5) or darker at center, however light beige to ocherish when dry, radially striate to the middle, hygrophanus when wet, margin projecting beyond the lamellae, crenulate. context thin, odor indistinct or slightly raphanoid, taste mild.

Lamellae. adnext to subfree, close to subclose, grey white to ligh grey, edge smooth to very finely pruinose

Stipe. $25-54 \times 1-1.7 \mathrm{~mm}$, cylindric, equal, straight, somewhat bent, or twisted, surface dry, pale orange white(6A2) to whitish upwards, light brown to dark brown at the base, longitudinally fibrillose, all over with finely whitish pruinose, hollow.

\section{Microscopic features (Fig. 3).}

Spore print white, Spores 5.7-7 × 4.8-5.2 $\mu \mathrm{m}$. broadly ellipsoid, ovoid, spinose, thin-walled, hyaline, inamyloid. Basidia 27.8-30.5 ×9-9.6 $\mu \mathrm{m}$, clavate, with (2)4-sterigmata, with basal clamp connection. with siderophilous granules. Hymenophoral trama regular. Cheilocystidia not seen. Pleurocystidia not seen. Pileipellis composed of parallel hyphae 3-7 $\mu \mathrm{m}$ across, septa with clamp connections

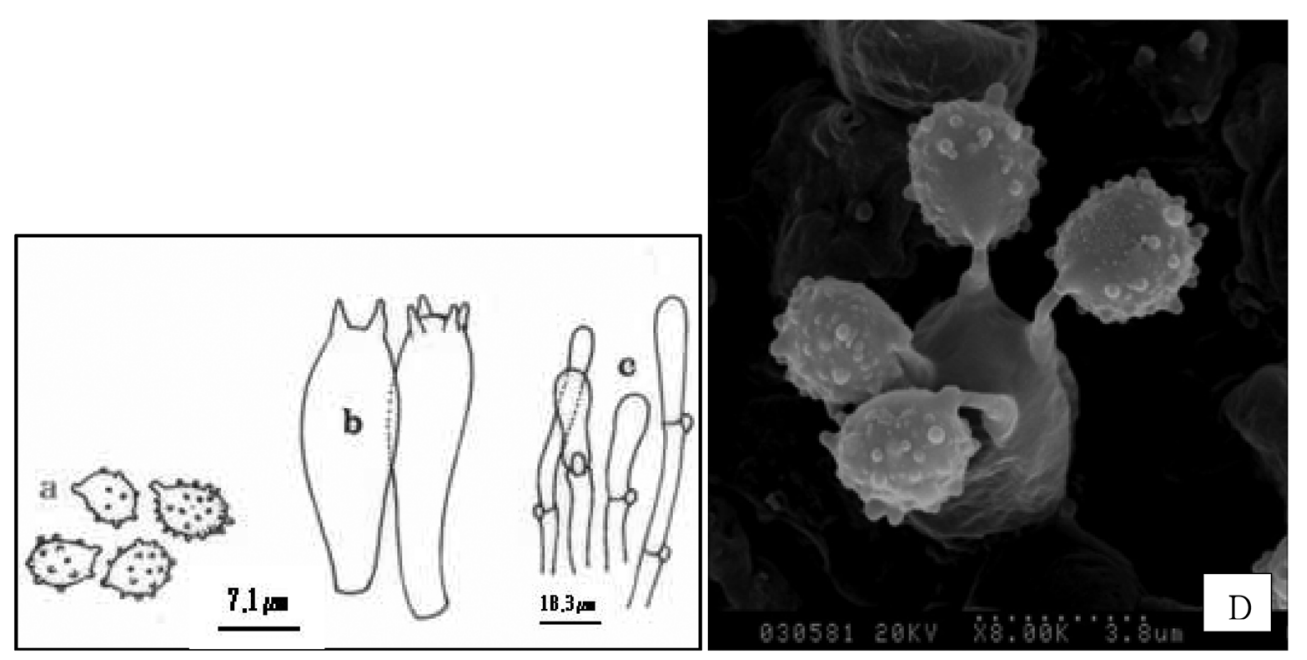

Fig. 3. Microscopic structures of Lyophyllum tylicolor. A. spores $(\times 1,000)$, B. basidia $(\times 1,000)$, C. cheilocystidia $(\times 400)$, D. scanning electron micrograph of a basidium \& four spores 
Habit \& Habitat. scattered or a few gregarious on leaves on the ground. in hardwood forests or mixed wood forests, Summer to Autumn, very rare.

Habit \& Habitat. Scattered or a few grouped on the soils in mixed forests in summer to autumn.

Specimens examined. Kariwang-san, Pyongchang-gun, Kangwon-do, Aug. 23, 1993. (HCCN:0120G), Collected by Y. S. Kim.

Remarks. This species is very similar microscopically and macroscopically to the other closely related "Tephrocybe" species in section Ornatisporinae Sing. The latter contains several species which are difficalt to differenciate, because they have variosly interpreted in the literatures, such as Lyophyllum erosa, L. tesquorum, L. plexipes and L. oldae. Bon(1977) constructed a key to bring order this confusion based on the descriptions of microscopic, ecological and other features. This taxa is seperated from the other closely related species by the silvicolous habit, $L$. tesquorum is characterized by the black brown pileus and on calcareous soils. L. erosa distinguished by the reddish brown pileus and graminicolous or heliophilic and L. oldae has a non striate, grey brown pileus mycenoid.

갓은 4-15 mm로 원추상종형-반구형이나 성장하면 반반 구형이고, 최종적으로 편평 하게 펴지며 중앙부위에 유두 상 돌기가 있다. 표면은 건성이고, 평활하거나 약간 분질 물이 있으나 성장하면 쉽게 탈락되며, 섬유질상이고, 갓의 끝부위는 등황백 색-옅은 등황백색을 띠며, 중앙부위는 암황색이고, 건조하면 베이지색-황토색을 띤다. 갓 끝은 주름살보다 길어 갓 깃을 형성하며, 조개형이다. 조직은 얇고, 냄 새는 불분명하거나 약간 밀가루냄새가 나며, 맛 은 부드럽다.

주름살은 끝붙은주름살-약간 떨어진 주름살이며, 약간 빽빽하고, 회백색-맑은 회 색을 띤다. 주름살날은 평활하 거나 미세한 분질상이다.

대는 크기가 $25-54 \times 1-1.7 \mathrm{~mm}$, 원통형이며, 상하굵기가 비슷하고, 곧으며 종종 굽어있거나 뒤틀리기도 한다. 표면은 상부 쪽은 옅은 등황백색-백색이고, 기부 쪽은 맑은 갈색암갈색을 띠며, 종으로 섬유질이 있고, 미세한 분질이 전 체에 있다.

포자는 크기가 5.7-7 × 4.8-5.2 $\mu \mathrm{m}$ 로 넓은 타원형, 난형 이며 침상돌기가 있고, 포 자벽은 얇으며, 무색이고, 비아 밀로이드이며, 포자문은 백색이다. 담자기는 크기가 27.8$30.5 \times 9-9.6 \mu \mathrm{m}$ 로 곤봉형이고, (2)4-개의 담자뿔이 있으며, 기부에 클램 프가 있다. 자실층조직은 평행형이다. 날시스
티디아와 측시스티디아는 없다.

갓표피상층은 폭 3-7 $\mu \mathrm{m}$ 인 평행균사로 구성되어 있으며, 모든 균사의 격막에는 클 램프가 있다.

발생시기 및 장소 : 여름-가을에 혼합림내 부식토상에 산생-소수 군생한다.

시험재료 : 강원도 평창군 가리왕산, 1993. 8. 23 (HCCN: $0120 \mathrm{G})$, 채집자: 김양섭

관찰 : 본 종은 현미경적 미세구조와 육안적 모양이 Section Ornatisporinae Sing. 내의 "Tephrocybe" 종들과 매우 유사하 다. 여기에 속하는 종들은 Lyophyllum erosa, L. tesquorum, L. plexipes and L. oldae. 등이 있으며, 문헌상에서 여러 가지로 해석 되기때문에 구분하기가 쉽지 않다. Bon(1977)은 현 미경적 미세구조, 생태적 특징 및 다른 특징들을 기초로 하여 이러한 문제를 해결하기 위하여 검색키를 만들 었다. 그 결과 L. tylicolor는 주로 솦속에 발생하는 습성을 가지고 있으며, L. tesquorum는 갓 흑갈색을 띠고 석회성분이 많은 토양에서 주로 발생하는 버섯이 며, L. erosa는 갓은 적갈색을 띠고, 솦 속이 아니고, 주로 초원에 발생하는 버섯 이며, L. oldae 는 갓의 표면에 선이 없고, 회갈색을 띠며, mycenoid 형 이란 점에서 특징적이다.

흰그늘버섯(신칭) Clitopilus scyphoides (Fr.) Singer, Farlowia 2: 554 (1946) var. scyphoides

Synonymy: Agaricus cretatus Berk. \& Broome, Ann. Mag. nat. Hist., Ser. 3 7: 373 (1861)

Agaricus scyphoides Fr., Syst. mycol. (Lundae) 1: 193 (1821)

Agaricus scyphoides Fr., Syst. mycol. (Lundae) 1: 193 (1821) var. scyphoides

Clitocybe scyphoides (Fr.) P.D. Orton, Trans. Br. mycol. Soc. 43(2): 174 (1960)

Clitopilus cretatus (Berk. \& Broome) Sacc., Syll. fung. (Abellini) 5: 702 (1887)

Clitopilus giovanellae var. omphaliiformis (Joss.) Joss. [as 'omphaliformis'], Bull. Soc. linn. Lyon, Num. Spéc. 10: 10 (1943)

Clitopilus omphaliiformis Joss., Bull. mens. Soc. linn. Lyon 10: 10 (1941)

Clitopilus scyphoides (Fr.) Singer, Farlowia 2: 554 (1946)

Clitopilus scyphoides f. omphaliiformis (Joss.) Noordel. [as 'omphaliformis'], Persoonia 12(2): 159 (1984)

Clitopilus scyphoides f. reductus Noordel., Persoonia 12(2): 159 (1984)

Clitopilus scyphoides var. omphaliiformis (Joss.) E. Ludw. [as 'omphaliformis'], Pilzkompendium (Eching) 1([2]): 62 
(2001)

Clitopilus scyphoides var. reductus (Noordel.) E. Ludw., Pilzkompendium (Eching) 1([2]): 63 (2001)

Omphalia scyphoides (Fr.) P. Kumm., Führ. Pilzk. (Zwickau): 106 (1871)

\section{Macroscopic features (Fig. 1E, 1F).}

Pileus. $3-12 \mathrm{~mm}$ wide, circular, oval to mytitiform, plane, somewhat, indented around center, somewhat undulate towards margin, which incurved for a long times. surface dry, pure white, sligthly uneven, finely velutinous-tomentose. Context thin, white, odor indistinct. taste mild.

Lamellae. decurrent, distant to subclose, white to pale pinkish. edge smooth, lamellulae usually (2)3- or multi-tiers.

Stipe. $3-6(10) \times \pm 1 \mathrm{~mm}$, cylindric, equal, central to excentric, rarely aborted. surface dry, white, with finely pilose, with white strigose at the base.

\section{Microscopic features (Fig. 4).}

Spores 5.4-7.6 $\times 3.2-4.5 \mu \mathrm{m}$, elliptical in side view, 6-8 angled in end view, smooth, indistinctly longitudinally striates. spore print dingy pink. Basidia 16.7-21.6 $\times 6.5-8.8 \mu \mathrm{m}$, cylindric clavate, (2)4-spored, without basal clamp connection. Cystidia not seen. Pileipellis compssed of periclinal to irregular hyphae 2.2-5.5 $\mu \mathrm{m}$ across, septa without clamps.

Habits \& Habitats. Summer to Fall, Solitary to gregarious among mosses and remains of plant on bare soils or on roadsides, very rare. on soil.

Specimens examined. Suwon-si, Gyonggi-do, July 29, 1999. ( HCCN:7718A). Collected by Y. S. Kim

Remarks. This taxa is very similar to Clitopilus prumulus (Scop.:Fr.)Kumm., However it differs from the latter by distinctly small fruit bodies, pure white, not strongly

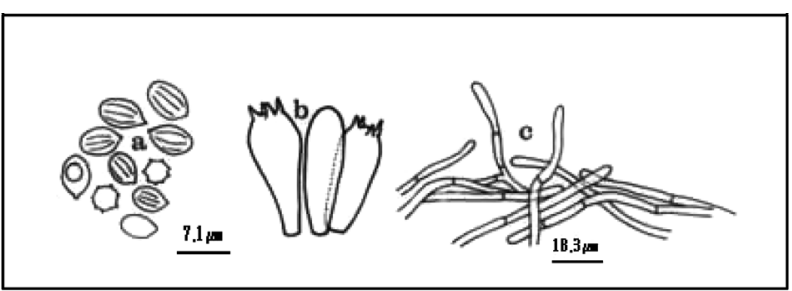

Fig. 4. Microscopic structures of Clitopilus scyphoides var. scyphoide. A. spores $(\times 1,000)$, B. basidia $(\times 1,000), \mathrm{C}$. pileipellis $(\times 400)$. decurrent lamellae.

갓은 크기가 3-12 mm로 초기에는 난형-형, 성장하면 편 평하게 되고, 중앙부위는 약간 우묵하게 들어 가 있으며, 성장 초기에는 갓의 끝부위는 안으로 굽어있고, 성장하면 파상 굴곡이 있다. 표면은 건조하며, 순백색이고, 미세한 벨벧상 모가 있다. 조직은 얇고, 백색이며, 냄새는 불분명 하고, 맛은 부드럽다.

주름살은 내린주름살이며, 성글거나 약간 성글고, 백색 이나 성장하면 분홍색을 띤다. 주름살날은 평활하고, 짧은 주름살은 (2)3-가지형 또는 그 이상이다.

대는 크기가 3-6(10) $\times \pm 1 \mathrm{~mm}$ 로 원통형이며, 중심형-편심 형이고, 드물게는 거의 대가 형성되지 않았다. 표면은 건 성이고, 백색이며, 미세한 가늘고 부드러운 모가 있고, 기 부에는 백색의 길고 성근 털이 있다.

포자는 크기가 5.4-7.6 × 3.2-4.5 $\mu \mathrm{m}$ 로 타원형이고 6-8각형 이며, 표면은 평활하 고, 불분명한 종으로 선이 있다. 포 자문은 어두운 분홍색이다. 담자기는 크기가 16.7-21.6× 6.5-8.8 $\mu \mathrm{m}$ 로 원통상곤봉형이며, (2)4-포자형이고, 기부에 클 램프가 없다. 시스티디아는 없다. 갓표피상층은 폭이 2.2$5.5 \mu \mathrm{m}$ 인 평행균사로 구성되어 있으며, 격막에 클램프가 없다.

발생시기 및 장소 : 여름-가을에 산림내 임도변 또는 나 지의 주로 이끼가 많은 토양 또는 부후목 주위에 산생-소수 무리져 발생한다. 매우 희귀종이다.

시험재료 : 경기도 수원시, 1999. 7. 29 (HCCN:7718A), 채집자: 김양섭.

관찰 : 본 종은 Clitopilus prunulus(Scop.:Fr.)Kumm와 매우 유사하나, 자실체가 매우 작으며, 순백색을 띠고, 긴 내린주름살이 아니란 점에서 다르다

꼬마외대버섯(신칭) Entoloma rusticoides(Gillet) Noordel., Persoonia 11(2): 150 (1981)

Synonymy: Claudopus rusticoides (Gillet) P.D. Orton, Mycologist 5(3): 126 (1991)

Eccilia rusticoides Gillet, Les Hyménomycètes ou description de tous les champignons (fungi) qui croissent en France (Alençon): 425 (1874)

Paraeccilia rusticoides (Gillet) Largent, Entolomatoid fungi of the Western United States and Alaska (Eureka): 376 (1994)

Rhodophyllus rusticoides (Gillet) J.E. Lange, Dansk bot. Ark. 2(no. 11): 40 (1921)

\section{Macroscopic features (Fig. 1G).}

Pileus $4-15 \mathrm{~mm}$ across, when young convex, later obtuse papilla in the center, margin incurved for a long time, 
crenulate, somewhat undulating. surface smooth, dark gray brown to umber brown, translucent-striates when wet, dry, pale beige brown, hygrophanous when dry, covered with finely tomentose, around center whitish fibrillose scales. Conntext thin, cream to whitish, Odor indistinct. Taste mild, in lit. faintly rancid.

Lamellae. decurrent, distant to subclose, pale gray beige when young, then brownish- pink, edge smooth.

Stipe. $8-25 \times 1-1.5 \mathrm{~mm}$, cylindric, equal, surface smooth, grey to ochre-brown, usually with white tomentose at the base, solid

\section{Microscopic features (Fig. 5).}

Spores 7.5-10.5 $\times 6.5-9.2 \mu \mathrm{m}$, 5-6angled, spore print reddishochre. Basidia 28.4-37.6 $\times 9.2-12.8 \mu \mathrm{m}$, cylindric to subclavate, without basal clamp. Cystidia not seen. Pileipellis composed of periclinal hyphae 3.5-13.5 $\mu \mathrm{m}$ wide, some hyphal ends exserted and up to $35 \mu \mathrm{m}$ wide, sometimes with pale brownish pigments, and sparsely encrusted, septa without clamps.

Habit \& Habitat. Summer to Fall, Solitary to gregarious in fields around lawn ground, roadsides or on naked soil.

Specimens examined. Suwon-si, Gyonggi-do, September 10, 1999 (HCCN: 7901A). Collected by Y. S. Kim.

Remarks. This species is very similar microscopically and macroscopically to the other closely related "Tephrocybe" species in section Ornatisporinae Sing. The latter contains several species which are difficalt to differenciate, because

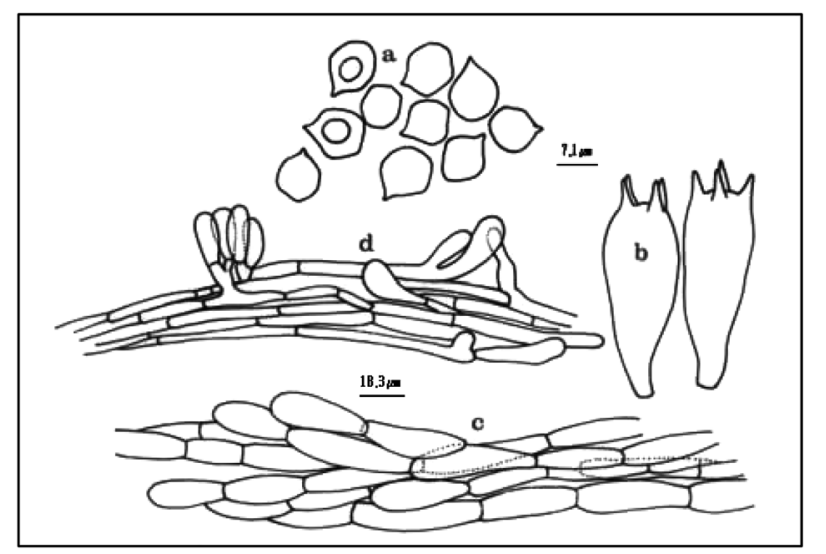

Fig. 5. Microscopic structures of Entoloma rusticoides. A. spores $(\times 1,000)$, B. basidia $(\times 1,000)$, C. pileipellis $(\times 400)$, D. stipitipellis $(\times 400)$. they have variosly interpreted in the literatures, such as L. erosa, L. tesquorum, L. plexipes and L. oldae. Bon(1977) constructed a key to bring order this confusion based on the descriptions of microscopic, ecological and other features. This taxa is seperated from the other closely related species by the silvicolous habit, L. tesquorum is characterized by the black brown pileus and on calcareous soils. L. erosa distinguished by the reddish brown pileus and graminicolous or heliophilic and L. oldae has a non striate, grey brown pileus mycenoid.

갓은 크기가 5-16 mm로 성장 초기에 반반구형이고 성 장하면 약간 펴지나 반반구 형을 유지하며 종종 중앙부위에 유두상 돌기가 있고, 대부분 중앙부위는 약간 들어간 홈이 있다. 표면은 습할 때 평활하고 반투명선이 나타나며 암희색황갈 색을 띠나, 건조하면 건변색 현상이 일어나며, 베이지색밝은 베이지갈색을 띠고, 미세한 섬유상 인피가 형성된다 갓 끝은 상당기간 동안 안쪽으로 굽어 있고, 성 장하면 다소 파상으로 굴곡이 있다. 조직은 얇고 옅은 황색-백색이며, 특별한 냄새가 없고, 맛은 부드럽다.

주름살은 대에 내린주름살이며, 성글고(긴주름살 13-17개), 어릴 때에는 옅은 회베이지색을 띠나, 성장하면 분홍색을 띤 갈색으로 짙어지고, 주름살날은 평활 하다.

대는 크기가 8-20 $\times 1-1.5 \mathrm{~mm}$ 로 원통형이며, 상하 굵기가 비슷하다. 표면은 평활 하며, 회색-황토갈색을 띠고, 대기 부에 백색의 균사모(tomentose)가 있으며, 속 은 차 있고, 다소 뺏뺏하다.

포자는 크기가 6.8-9.5 6.2-8.7 $\mu \mathrm{m}$ 로 5-6각형이고, 포 자문은 분홍황토색이다. 담자기는 크기가 27.8-38.2 × 8.5$12.7 \mu \mathrm{m}$ 로 원통형-편복상곤봉형이고 4-포자 형이나 드물게는 2-포자형도 있으며, 기부에 클램프가 없다. 시스티디아는 없다. 갓표피상층은 균사의 폭이 3-14.5 $\mu \mathrm{m}$ 인 평행균사로 구성되어 있으며, 균사벽에 옅은 갈색의 색소가 있고, 격 막에 클램프가 없다.

발생시기 및 장소 : 여름 가을에 잔디밭 길가 또는 둑에 산생-소수 무리져 발생 한다.

시험재료 : 경기도 수원시, 1999. 9. 10 (HCCN:7901A), 채 집자: 김양섭.

관찰 : 본종은 모양이 솔밭버섯형이며, 매우 작고 갓의 중앙부위가 배꼽처럼 들어 간 홈이 있고, 시스티디아가 없다는 점에서 유럽의 종 과 잘 부합되며, 모양과 크기가 유사한 Entoloma rhodoclix (Lasch.) Mos.는 균사에 클램 프가 있으며, 얇고, 호야형의 날시스티디아가 있다는 점에 서 본 종과 다르다.

치마젓버섯(신칭) Lactarius uyedae Singer, Nova Hedwigia 
40: 436-438 (1985) [1984]

Synonymy: Pleurogala uyedae (Singer) Redhead \& Norvell, Mycotaxon 48: 377 (1993)

\section{Macroscopic features (Fig. 1H).}

Pileus 3-12 mm wide, kidney to flabelliform, or conchate, margin incurved when young, surface dry, whitish, later dark yellow, sligthly uneven, radially rugullose toward margin. context thin, membranous, white, Latex white, not change, taste acrid. odor indistinct.

Lamellae decurrent to adnate, distant, white, later pale yellow. edge smooth, intervenose, lamellae 7-12 individuals, lamellulae usually (1)2- or 3- tiers.

Stipe 1-2 $\times \pm 1 \mathrm{~mm}$, cylindric, equal, central to excentric, rarely aborted. surface dry, white, with finely tomentose at the base.

\section{Microscopic features (Fig. 6).}

Spores 8.2-9.1 × 7.5-6.4 $\mu \mathrm{m}$, subglose to broadly elliptical, with reticulate-cristate, ornamentation almost forming \pm complete network, hyaline, ornamentation strongly amyloid, hilar appendix small. Basidia 52-57 × 9.1-10 $\mu \mathrm{m}$, cylindric clavate, 4-spored, with clamp connection. Cheiloystidia 66-171.6× 8.8-11 $\mu \mathrm{m}$. cylindric, somewhat thick-walled, hyaline, scattered, apical acute. Pleurocystidia almost similar to Cheiloystidia in shape and size. hymenium layer trichoderm. Pileipellis compssed of globose to subglobose cells $22-37.4 \times 22-26.4 \mu \mathrm{m}$ across, in catenulate or regular epithelium to irregular epithelium, interspersed with thick-walled(2-3 $\mu \mathrm{m}$ thick), hyaline setiform $61.6-186.2 \times 5.5-12.1 \mu \mathrm{m}$ part hyphal end exserted, septa without clamps.

Habit \& Habitat. Summer to Fall, Solitary to gregarious among mosses and remains of plant on bare soils or on roadsides, very rare on soil.

Specimens examined. Youngsil, Jungmoon, Seoguipo-si, Jeju-do, September 6. 1999 (HCCN: 7867A). Collected by S. J. Seok.

Remarks. This taxa is very similar to Clitopilus prumulus (Scop.:Fr.)Kumm. However it differs from the latter by distinctly small fruit bodies, pure white, not strongly decurrent lamellae.

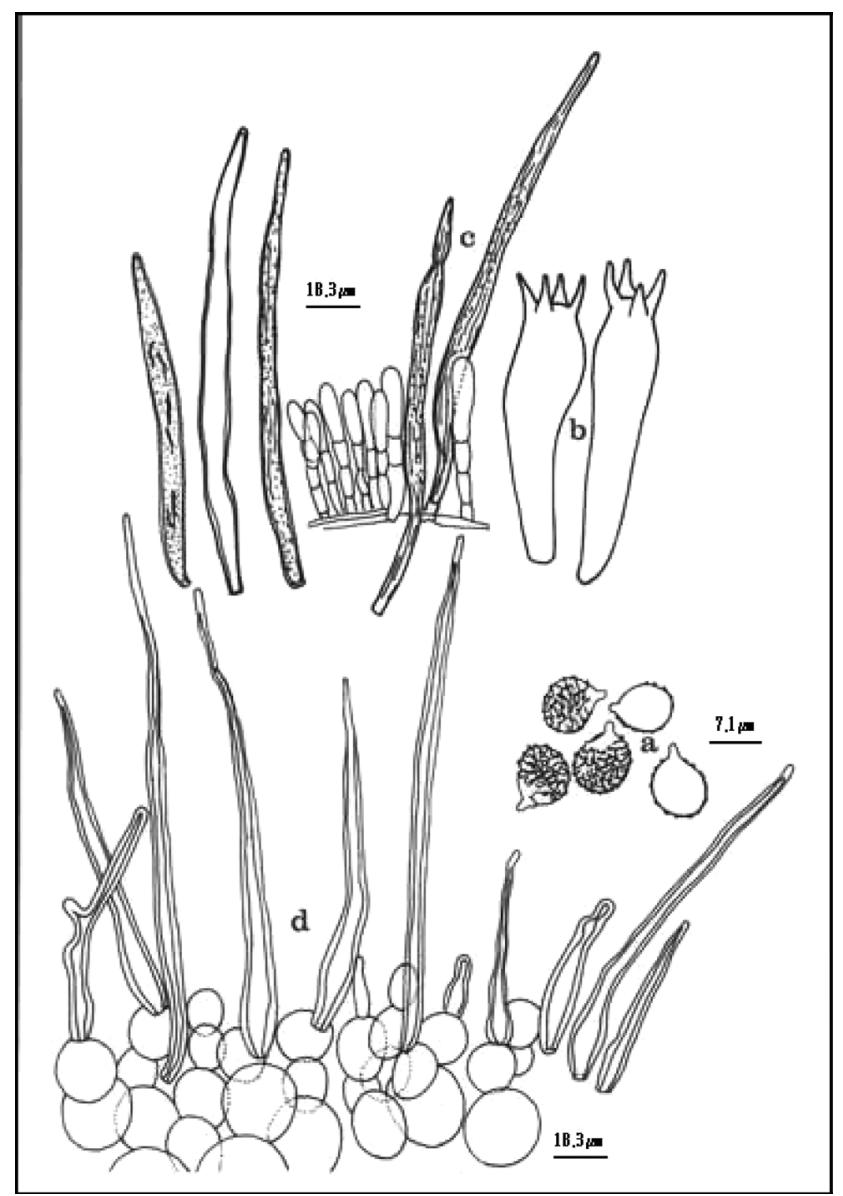

Fig. 6. Microscopic structures of Lactarius uyedae. A. spores $(\times 1,000)$, B. basidia $(\times 1,000)$, C. pleurocystidia \& cheilocystidia $(\times 400)$, D. pileipellis $(\times 400)$.

이며, 갓 끝부위는 안쪽 으로 말려있으나 성장하면 편평하게 펴진다. 표면은 점성이 없고, 초기에는 백색 이나 성장하면 옅은 암황색으로 되며, 미세한 섬유상 모가 있다. 조직은 얇고 막 질이며, 백색이고, 유액은 백색이며, 변색되지 않고, 매운맛이 있다.

주름살은 대에 완전붙은주름살-성글고 어릴 때에는 백 색이나 성장하면 옅은 황 색을 띠고, 주름살사이에 간맥 (intervenose)이 있으며, 주름살날은 평활하다.

대는 크기가 1-2 $\times 1-1.5 \mathrm{~mm}$ 로 갓의 중심 편심 또는 측면에 부착하여 있으며, 표 면은 미세한 균사모로 덮혀 있다.

포자는 크기가 6.8-8.4 ×5.4-6.7 $\mu \mathrm{m}$ 로 광타원형-광난형 이며, 표면은 돌기와 망 목상으로 되어 있다. 담자기는 크 기가 27.8-38.2 × 8.5-12.7 $\mu \mathrm{m}$ 로 곤봉형이며 4-포자형이나 드물게는 2-포자형도 있으며, 기부에 협구가 없다. 날시스 티디아는 크기가 48.4-68.8 $\times$ 8.2-9.6 $\mu \mathrm{m}$ 로 원통상 방추형-원 통상 곤봉형이나 정단 부위에 유두상 돌기 또는 유연하게 신장되어 있으며, 세포벽은 얇고, 무색이다. 측시 스티디아는 모양과 크기가 날시스티디아와 같다. 갓시스티디아는 크 기가 36.5-107 ×5.3-8.4 $\mu \mathrm{m}$ 로 원통형으로 정단부위가 신 
장되어 있거나 유두상 돌기가 있다.

발생시기 및 장소 : 여름에 혼합림 내 노출된 이끼가 많은 토양 또는 부후목 위에 산생-소수 군생한다. 매우 희귀종 이다.

시험재료 : 제주도 서귀포시 중문 영실 표고재배용 썩은 원목 주위 지상, 1999. 9. 6 (HCCN:7867), 채집자: 석순자

관찰 : 본 종과 근연종으로서 Lactarius panuoides Sing. 등 3종이 열대 아메리 카에서 발견되어 알려져 있다. 자 실체의 모양은 느타리 형으로 대가 갓의 편심 또는 측생 으로 부착되어 있다는 점과 전체가 백색이고, 작으며, 잘 썩은 부후목 상에 발생한다는 점이 특징적이다.

\section{적요}

저자들은 한국산 균류의 종다양성 조사를 실시하여 왔 으며, 그 중 주름버섯목 의 무명버섯속, 만가닥버섯속, 그 늘버섯속, 외대버섯속과 젖버섯속에 속하는 5종 (장미무
명버섯, 애만가닥버섯, 흰그늘버섯, 꼬마외대버섯과 치마 젖버섯)이 한국미 기록종으로 확인되었다. 미기록종에 대한 미세구조와 특징을 기술하고 한국명을 신칭하여 보고한다. 사용된 모든 표본은 국립농업과학원 식물균류표본보존센 타 $(\mathrm{HCCN})$ 에 보존되어 있다.

\section{참고문헌}

Breitenbach, J. and Krnzlin, F. 1984-2000. Fungi of Switzerland, vols. 1-5. Lucerne: Verlag Mykologia.

Imazeki, R. and Hongo, T. 1987-89. Colored illustrations of fungi of Japan, vols. 1-2. Osaka: Hoikusha Publishing Co.

Largent, D. L., Johnson, D. and Watling, R. 1977. How to identify mushroom to genus, vol. 3. Microscopic features. Eureka: Mad Ricer.

Kornerup, A. and Wanscher, J. H. 1978. Methuen handbook of colour. London: Methuen.

Singer, R. 1986. Singer R. The Agaricales in modern taxonomy. $4^{\text {th }}$ ed. Koeningstein: Koeltz Scientific Books; 1986.

Index Fungorum [Internet]. Index Fungorum; c2008 [cited 2011 Mar 1]. Available from: http://www.indexfungorum.org/Nmes/ Names.asp. 